\title{
Depression and sexual risk behavior among long-distance truck drivers at roadside wellness clinics in Kenya
}

\author{
Matthew L Romo ${ }^{1,2}$, Gavin George ${ }^{3}$, Joanne E Mantell ${ }^{4}$, Eva Mwai ${ }^{5}$, Eston Nyaga ${ }^{5}$, Michael Strauss ${ }^{3}$, Jacob 0 \\ Odhiambo $^{5}$, Kaymarlin Govender ${ }^{3}$, Elizabeth A Kelvin ${ }^{\text {Corresp. } 1}$ \\ 1 Department of Epidemiology and Biostatistics \& Institute for Implementation Science in Population Health, Graduate School of Public Health and Health \\ Policy, City University of New York, New York, New York, USA \\ 2 School of Public Health, Li Ka Shing Faculty of Medicine, The University of Hong Kong, Hong Kong, Hong Kong SAR \\ 3 Health Economics and HIV and AIDS Research Division, University of KwaZulu-Natal, Durban, South Africa \\ 4 HIV Center for Clinical and Behavioral Studies, Department of Psychiatry, Division of Gender, Sexuality, and Health, New York State Psychiatric Institute \\ \& Columbia University Medical Center, New York, New York, USA \\ 5 North Star Alliance, Nairobi, Kenya \\ Corresponding Author: Elizabeth A Kelvin \\ Email address: elizabethakelvin@gmail.com
}

Background: Truck drivers in sub-Saharan Africa are at high risk for both mental health disorders and sexually transmitted infections. We sought to determine the prevalence of depression among a sample of long-distance truck drivers seeking services at roadside wellness clinics in Kenya and explore the relationship between depression and sexual risk behavior. Methods: We used data from an interviewer-administered questionnaire from 284 truck drivers in Kenya who participated in a randomized controlled trial evaluating whether offering oral HIV self-testing could increase HIV test uptake. Depression was categorized based on the Patient Health Questionnaire (PHQ-9) score, with a score $\geq 10$ indicative of probable major depressive disorder (MDD). Sexual risk behavior was operationalized as the number of condomless sex partners in the past 6 months. Results: The mean participant age was 36.9 years, $83.0 \%$ were married, and $37.0 \%$ had a secondary school education or higher. Overall, $24 \%$ of participants had probable MDD, and $58.2 \%$ reported having one condomless sex partner in the past 6 months, whereas $27.3 \%$ reported having had two or more. In a multivariable Poisson regression model adjusted for demographic and other relevant variables, including number of sex partners, MDD was significantly associated with a greater number of condomless sex partners (adjusted prevalence ratio $1.63,95 \%$ confidence interval: $1.25-2.12, \mathrm{p}<.001$ ). General self-efficacy significantly mediated the association between MDD and number of condomless sex partners. Conclusions: The high prevalence of depression highlights the need to test the feasibility and acceptability of mental healthcare interventions for this population, possibly integrated with HIV prevention services. Future research is needed to better understand the association between depression and sexual risk behavior, as well as the role of self- 
efficacy. 
1

2

3

4

5

6

7

8

9

10

11

12

13

14

15

26

27

28

\section{Depression and sexual risk behavior among long-distance truck drivers at roadside}

\section{wellness clinics in Kenya}

Matthew L. Romo ${ }^{1,2}$, Gavin George ${ }^{3}$, Joanne E. Mantell ${ }^{4}$, Eva Mwai ${ }^{5}$, Eston Nyaga ${ }^{5}$, Michael

Strauss $^{3}$, Jacob O. Odhiambo ${ }^{5}$, Kaymarlin Govender ${ }^{3}$, Elizabeth A. Kelvin ${ }^{1}$

${ }^{1}$ Department of Epidemiology and Biostatistics \& Institute for Implementation Science in Population Health, Graduate School of Public Health and Health Policy, City University of New York, New York, New York USA

${ }^{2}$ School of Public Health, Li Ka Shing Faculty of Medicine, The University of Hong Kong, Hong Kong Hong Kong SAR

${ }^{3}$ Health Economics and HIV and AIDS Research Division, University of KwaZulu-Natal, Durban, South Africa

${ }^{4} \mathrm{HIV}$ Center for Clinical and Behavioral Studies, Department of Psychiatry, Division of Gender, Sexuality, and Health, New York State Psychiatric Institute \& Columbia University Irving Medical Center, New York, New York USA.

${ }^{5}$ North Star Alliance, Nairobi, Kenya

Corresponding Author:

Elizabeth A. Kelvin ${ }^{1}$

55 West 125th Street, New York, NY 10027, USA. e-mail address: elizabethakelvin@gmail.com 


\section{Abstract}

30 Background: Truck drivers in sub-Saharan Africa are at high risk for both mental health

31 disorders and sexually transmitted infections. We sought to determine the prevalence of

32 depression among a sample of long-distance truck drivers seeking services at roadside wellness

33 clinics in Kenya and explore the relationship between depression and sexual risk behavior.

35 Methods: We used data from an interviewer-administered questionnaire from 284 truck drivers in Kenya who participated in a randomized controlled trial evaluating whether offering oral HIV self-testing could increase HIV test uptake. Depression was categorized based on the Patient Health Questionnaire (PHQ-9) score, with a score $\geq 10$ indicative of probable major depressive disorder (MDD). Sexual risk behavior was operationalized as the number of condomless sex partners in the past 6 months.

Results: The mean participant age was 36.9 years, $83.0 \%$ were married, and $37.0 \%$ had a secondary school education or higher. Overall, 24\% of participants had probable MDD, and $58.2 \%$ reported having one condomless sex partner in the past 6 months, whereas $27.3 \%$ reported having had two or more. In a multivariable Poisson regression model adjusted for demographic and other relevant variables, including number of sex partners, MDD was significantly associated with a greater number of condomless sex partners (adjusted prevalence ratio 1.63, 95\% confidence interval: $1.25-2.12, \mathrm{p}<.001)$. General self-efficacy significantly mediated the association between MDD and number of condomless sex partners.

51 Conclusions: The high prevalence of depression highlights the need to test the feasibility and

52 acceptability of mental healthcare interventions for this population, possibly integrated with HIV 
53 prevention services. Future research is needed to better understand the association between

54 depression and sexual risk behavior, as well as the role of self-efficacy.

55

56

57

58

59

60

61

62

63

64

65

66

67

68

69

70

71

72

73

74

75

76

77

78

79

80

81

82

83

84

85

86

87

88

89

90

91 Introduction 
92 Few published studies have comprehensively explored the epidemiology of depression among

93 truck drivers and none, to our knowledge, have done so in sub-Saharan Africa. Long-distance

94 truck drivers may have a high prevalence of depression (and possibly other mental health

95 disorders) due to occupational related stressors [1-4], such as road hazards, fixed delivery

96 deadlines, and irregular sleeping schedules [5]. Globally, several studies have estimated the

97 prevalence of depression among truck drivers, but these estimates have varied by country,

98 ranging from $14 \%$ to $70 \%[6-11]$.

99

100 Truck drivers are also at high-risk of HIV infection because of the high rates of sexual risk

101 behavior, including engaging in condomless sex and having multiple partners [12-15]. A small

102 number of studies in sub-Saharan Africa have explored the relationship between depression and

103 sexual risk, including in a general population at risk for HIV infection in South Africa [16, 17]

104 and among social networks of young men in Tanzania [18]. Although this relationship is

105 complex, one possible explanation may be that maladaptive thought patterns arising from

106 depression, such as those related to impulsivity and hopelessness [19], might lead to the adoption

107 of risky behavior and increase the propensity for self-harm. In other words, depression might

108 lead to increased sexual risk behavior. General self-efficacy, which can be defined as “people's

109 belief in their ability to influence events that affect their lives" [20], might mediate this

110 association, as suggested by previous studies in sub-Saharan Africa [21-23].

112 In this study, we assessed the prevalence of depression and explored its association with sexual

113 risk behavior in a sample of long-distance truck drivers seeking services at two roadside wellness 
114 clinics in Kenya. Additionally, we explored whether general self-efficacy mediated the

115 association between depression and sexual risk behavior.

116

117

118

119

120

121

122

123

124

125

126

127

128

129

130

131

132

133

134

135

136

137

138

139

\section{Materials \& Methods Study procedures}

We used cross-sectional data collected as part of a randomized controlled trial evaluating whether offering HIV testing options (i.e. provider-administered blood-based [finger prick] rapid HIV test or a supervised oral self-administered rapid HIV test [OraQuick In-Home HIV Test] in the clinic or a self-test kit for home use) compared with the standard of care (i.e. only offering the provider-administered blood test) would increase HIV testing rates among truck drivers in Kenya. The methods and results of this trial are described in detail elsewhere [24].

Participants were recruited from two North Star Alliance roadside wellness clinics located along the northern transport corridor in Nakuru County, Kenya, one of the highest HIV prevalence areas in the country $[25,26]$. The North Star Alliance provides healthcare services, including sexually transmitted infection and HIV testing and treatment [27], to key populations in transport corridor communities, including truck drivers and sex workers. At the time of this study, the North Star Alliance had 36 clinics in Africa, eight of which were in Kenya. Together, the two clinics included in this study served about 400 clients weekly, $30 \%$ of whom were long-distance truck drivers. Any male truck driver who visited either of the two clinics from October to December 2015 for services other than HIV treatment, was informed about the research study 
140 and, if interested, was referred to a fieldworker for information and eligibility screening.

141 Eligibility criteria were: 1) at least 18 years old, 2) male (based on observation), 3) employed as

142 a long-distance truck driver (anyone who works to make deliveries locally would be classified as

143 a community resident and not eligible for our study), 4) primary residence in Kenya, 5) able to

144 speak English or Kiswahili, 6) self-reported HIV-negative or unknown HIV status, 7) able to

145 sign the consent form, and 8) willing to receive payment for participation via MPesa, a cell

146 phone-based money transfer system widely used in Kenya. Overall, 319 men were referred for

147 eligibility screening, of whom 305 were enrolled in the study. Informed consent was obtained

148 from all participants.

149

150 Fieldworkers administered a baseline interview to truck drivers who met the eligibility criteria

151 and consented to participate in the study. The baseline interview included questions about

152 demographic characteristics and risk behavior, and several psychometric scales, including 153 general self-efficacy. Following the baseline interview, participants were offered HIV testing

154 with options dependent on randomization arm (i.e. choice of an alternative HIV testing modality

155 vs. standard provider-administered blood test). After undergoing or refusing HIV testing,

156 appointments were made for a follow-up interview at six months. At the six-month interview,

157 which was completed over the phone in most cases, research staff administered the Patient

158 Health Questionnaire (PHQ)-9 [28] and asked about HIV testing in the past six months. The

159 questionnaires were developed in English and Kiswahili, and the Kiswahili translation was

160 translated and back-translated to English into ensure accuracy. Interviews were conducted in

161 Kiswahili, English, or both, depending on the participant's preference. The study procedures

162 were approved by the City University of New York Institutional Review Board (\#2015-0645), 
163 the Kenya Medical Research Institute Ethics Committee (\#541), and the University of KwaZulu-

164 Natal Biomedical Research Ethics Committee (BFC025/15), and were in accordance with the 1651964 Helsinki declaration and its later amendments.

166

\section{Measures}

168

169

170

171

172

173

174

175

176

177

178

179

180

181

182

183

184

185

Sexual risk behavior (main outcome of interest)

Number of condomless sex partners was used as a measure of sexual risk behavior and was determined by asking participants how many female and male condomless sex partners they had in the past 6 months. Participants who did not have sex in the past 6 months $(n=6)$ were categorized as having zero condomless sex partners. Only one reported ever having anal sex with another man. We retained this variable as a numeric, but also categorized responses (none, one, two or more) in bivariate analyses.

\section{Depression (main exposure of interest)}

Depression was assessed with the PHQ-9, a widely used and validated nine-item questionnaire asking about each Diagnostic and Statistical Manual of Mental Disorders-IV depressive symptom within the last 2 weeks [28]. Each item is scored based on symptom frequency, from 0 ("not at all"), 1 ("several days"), 2 ("more than half the days"), or 3 ("nearly every day"), with scores can ranging from 0 to 27 . The PHQ-9 has been formally validated among general adult populations using an acceptable gold standard (i.e. psychiatric clinician diagnosis using Schedules for Clinical Assessment in Neuropsychiatry or Mini International Neuropsychiatric Interview) in East African primary healthcare settings [29, 30]. We constructed a summary score by summing responses to the nine questions allowing up to one item to be left unanswered; only 
186 two participants had any missing responses, and for these two participants, only one item was

187 missing, so no one was excluded. The standardized Cronbach's alpha for the PHQ-9 in our study

188 sample was 0.88 , indicating good to excellent internal consistency. Scores were categorized as

189 no/minimal depression (score 0-4), mild depression (score 5-9), and moderate-severe depression

190 (score $\geq 10$ ). A score of $\geq 10$ has $88 \%$ sensitivity and specificity for major depressive disorder

191 (MDD) [28].

192

193

Demographic characteristics, self-efficacy, and other risk behavior

194 In the baseline interview, participants were asked their age, religion, educational attainment, and

195 marital status. Age was based on reported age at their last birthday (in years). Religion was

196 categorized as Christian (i.e. Protestant, Catholic) or non-Christian (i.e. Muslim, Hindu,

197 traditional African, and no religion). Educational attainment was categorized as having

198 completed at least secondary school vs. less than a secondary school diploma (i.e. no education,

199 some primary school, completed primary school only, or some secondary school). Marital status

200 was categorized as currently married (either legal or common-law) vs. unmarried (including

201 divorced/separated, widowed or single).

202

203 Average monthly income from truck driving was determined based on responses to the question

204 "about how much money do you earn in an average month driving a truck?" and those who were 205 unable or unwilling to specify their income were then asked "could you tell me if your income is 206 less than 8,000 Kenyan shillings (Ks), 8,000-16,000 Ks, 16,001-24,000 Ks, 24,001-50,000 Ks, or $207>50,001 \mathrm{Ks}$ ?" At the time of the study, $100 \mathrm{Ks}$ was worth approximately 1.00 US dollar (USD). 208 Income was dichotomized at about the first quartile into mid-high income ( $\geq 240$ USD) vs. low 
209 income ( $<240$ USD). Length of time worked as a truck driver was determined by asking

210 participants how many months and years they had worked as a truck driver. Driving

211 accompanied or not was determined by asking participants if they usually drive alone or if

212 someone else rides with them (e.g., assistant, main partner, non-main partner, family member,

213 etc.). Days away from home in the past month was determined by asking participants how many

214 nights they were away from home travelling for work in the past month.

215

216 General self-efficacy was measured using a 10-item scale [31], previously validated in a general

217 non-white South African population [32], which presents statements related to belief in one's

218 confidence to cope with a broad range of stressful or challenging demands. Response options

219 were on a four-point Likert scale from 'not at all true' to 'exactly true', with a possible total

220 score range of 10-40. We constructed a summary score by summing responses to the 10

221 questions allowing for one of the items to be left unanswered; only three participants had any

222 missing responses and they were missing only one item. Cronbach's alpha for this scale in our

223 sample was 0.89 , indicating good to excellent internal consistency.

224

225 Number of sex partners was determined by asking how many people they had sexual intercourse

226 with in the past 6 months, asking separately for female (vaginal/anal intercourse) and male (anal

227 intercourse) partners. Alcohol use was determined by asking how often the participant had drinks

228 containing alcohol in the past year. Similarly, illicit drug use was determined by asking how

229 often the participant used drugs in the past year, with marijuana and cocaine listed as examples.

230 Response options for both questions were 'at least once a day,' 'a few times a week but not every

231 day,' 'a few times a month but not every week,' 'a few times a year but not every month,' and 
232 'never.' We recoded these variables into two separate indicators for having consumed any

233 alcohol or drugs in the past year (both versus none) for bivariate analyses. However, as there

234 were very few reports of drug use and all participants who reported drug use also reported

235 alcohol use, only the alcohol use variable was included in the regression models.

236

\section{Statistical analysis}

238 We first described the sample overall and by depression category. We then used bivariate

239 statistical tests (Pearson's Chi-Square, Fisher's exact, and Kruskal-Wallis) to identify significant

240 differences in the distribution of variables by depression category. We then ran Poisson

241 regression models with number of condomless sex partners as the dependent variable. We ran

242 crude models, then a multivariable model that included all variables explored in bivariate

243 analyses (with the addition of clinic of enrollment). Next, we ran a multivariable model with

244 imputed data to address potential bias due to missing data. The multivariable model had about

$24525 \%$ missing data, so we ran 25 imputations to achieve reliable p-values and standard errors [33].

246 We used fully conditional specification for the imputation method (logistic for classification

247 variables and predictive mean matching for numeric variables) [34] with all variables in the

248 model used to impute missing values. We then re-ran our multivariable model with the imputed 249 data.

250

251 Finally, we assessed whether general self-efficacy mediated the association between MDD

252 (PHQ-9 score $\geq 10$ ) and number of condomless sex partners. This analysis was conducted using a

253 SAS Macro developed by Valeri and VanderWeele [35], with mediation methodology from Pearl

254 [36]. The Macro used a bootstrapping approach with 100 samples to generate crude prevalence 
255 ratios (cPRs) and 95\% CIs for the natural direct effect and natural indirect effect of the

256 association between MDD and number of condomless sex partners [35]. Presence of a

257 statistically significant natural indirect effect was evidence of mediation.

258

259 All analyses were conducted in SAS 9.4 (SAS Institute Inc., Cary, NC) and the significance level 260 was set at a two-sided $\alpha$ of 0.05 .

261

262

263

264

265

266

267 268

269

270

271

272 273

274 275 276

277

278 The mean and median scores on the PHQ-9 were $5.2(\mathrm{SD}=5.0)$ and 4.0 (interquartile range $279[\mathrm{IQR}]=9.0)$, respectively. Upon categorizing participants, 157 (55.3\%) had none/minimal 280 depression, 59 (22.8\%) had mild depression, and 68 (24.0\%) had moderate-severe depression 
281 (probable MDD) (Table 1). The prevalence of any symptom frequency in the past 2 weeks based 282 on the PHQ-9 was: low energy (50.7\%), trouble concentrating (50.4\%), anhedonia, (little interest 283 or pleasure in doing things) $(48.8 \%)$, appetite problems $(44.2 \%)$, feeling depressed $(40.8 \%)$, 284 sleep problems (41.2\%), low self-esteem (38.3\%), psychomotor problems $(30.6 \%)$, and 285 suicide/self-harm ideation (19.4\%).

286

287 Bivariate analysis results

288 In bivariate analyses, there were significant differences in the distribution of monthly income, 289 years worked as a truck driver, general self-efficacy, drug use, and number of condomless sex 290 partners by depression category. Participants with lower monthly trucking income (<240 USD) 291 vs. higher monthly trucking income ( $\geq 240$ USD) more often had moderate-severe depression 292 (38.0\% vs. $20.3 \% ; \mathrm{p}=.010)$. Truck drivers with moderate-severe depression vs. no/minimal 293 depression tended to have been in the occupation for a shorter period of time (mean years: 7.6 vs. 294 9.2; $\mathrm{p}=.016)$. General self-efficacy scores were lower for participants with depression (mean 295 score 38.2 [none/minimal depression], 35.3 [mild depression], 33.7 [moderate-severe 296 depression]; $\mathrm{p}<.001)$. Participants who reported drug use were more likely to have depression $297(0.0 \%$ [no/minimal depression], 11.1\% [mild depression] and 88.9\% [moderate-severe 298 depression]). Participants with moderate-severe depression were also more likely to have more 299 condomless sex partners vs. participants with no/minimal depression (mean number of partners: 2.2 vs. $1.2 ; \mathrm{p}=.003)$. (Table 1$)$

301 
303 In the crude Poisson regression model, moderate-severe depression (vs. none/minimal

304 depression) was a significantly associated with number of condomless sex partners (crude

305 prevalence ratio $1.80, \mathrm{p}<.001)$. This remained significant in the multivariable Poisson regression

306 model (adjusted prevalence ratio [aPR] 1.63, $\mathrm{p}<.001$ ). For this model, the Pearson chi-square

307 value divided by the degrees of freedom was 0.92 , indicating that under- and over-dispersion

308 were not present. A goodness-of-fit chi-squared test was not significant $(p=.814)$, indicating

309 reasonable model fit. In the multivariable model with imputed data, the associations between

310 depression and condomless sex partners remained similar (mild depression: aPR 1.22, $\mathrm{p}=.124$;

311 moderate-severe depression: aPR 1.62, $\mathrm{p}<.001$ ). (Table 2)

312

313 Mediation analysis results

314 In the mediation analysis for general self-efficacy, the natural direct effect was not statistically

315 significant (cPR 1.40; 95\% CI: 0.94, 1.90) and the natural indirect effect was significant (cPR

$3161.24 ; 95 \%$ CI: $1.14,1.44$ ) for the association between moderate-severe depression and number of

317 condomless sex partners.

318

319 Discussion

320 We found high prevalence of probable MDD (24\%) in this sample of truck drivers. When 321 comparing across studies that also used the PHQ-9 from non-community-based samples, this

322 estimate was higher than a sample of HIV-positive adult men attending clinics in Uganda (12\%)

323 [21], but lower than in a study among adult men who have sex with men (MSM) in coastal

324 Kenya enrolled in an HIV research study (42\%) [37]. Nationally representative data on

325 depression in the general population in Kenya are scant. According to the 2003 World Health 
326 Survey in Kenya, 5.5\% of men reported having been diagnosed with depression in the past 12

327 months [38]. Although we did not evaluate occupational stressors in this study, they may help

328 explain this high prevalence of depression and might have a similar effect on mental health as the

329 stressors reported by other high-risk groups, such as stigma-related abuse reported by MSM [39].

330 Currently, the North Star Alliance does not offer mental health screening, diagnosis, and

331 treatment at their roadside wellness clinics in East Africa; however, the results of this study

332 suggest a need for such services. A next step that should be considered is piloting mental

333 healthcare services integrated with existing HIV prevention and treatment services. Furthermore,

334 it will be important to identify other co-morbidities that can be addressed so as to provide more

335 holistic care to this population.

336 Truck drivers with moderate-severe depression had roughly $60 \%$ more condomless sex partners 337 compared with those with no/minimal depression, after adjusting for demographic variables and 338 number of sex partners. Although we cannot determine whether depression led to an increase in 339 sexual risk behavior because our study was cross-sectional, this finding is consistent with a

340 prospective study among men and women in South Africa, which found that baseline depressive 341 symptomatology was associated with failure to use a condom at last sex during the follow-up 342 interview [17]. These findings are supported by Beck's cognitive theory of depression whereby 343 negative feelings associated with depression can ultimately lead to negative behavioral reactions 344 to situations [40], such as not using a condom when presented with the opportunity for sexual 345 intercourse.

347 In our mediation analysis, the indirect effect (i.e. the effect of depression on sexual risk behavior 348 that acts through self-efficacy) was statistically significant and the natural direct effect (i.e. the 
349 effect of depression on sexual risk behavior unexplained by general self-efficacy) was not

350 statistically significant, thus suggesting self-efficacy as a mediator. In other words, depression

351 might negatively affect an individual's confidence to cope with stressful situations and perform

352 tasks, and consequently, this lower self-efficacy encourages an individual to engage in higher

353 sexual risk behavior. Self-efficacy is a broad construct, so there may be multiple explanatory

354 pathways between self-efficacy and sexual risk behavior, for example, pathways related to self-

355 esteem, optimism about the future, or belief in ability to prevent sexually transmitted infections

356 [41]. Other studies from sub-Saharan Africa have also found that self-efficacy was a mediator of

357 this association [21-23], but have also been cross-sectional. Bandura's Social Cognitive Theory

358 [42] might suggest that low self-efficacy could be a cause of depression implicating it as a

359 confounder. A recent study among adolescents examining the bidirectional association found that

360 depression resulted in negative changes in self-efficacy, rather than the other way around [43].

361 Thus, further research is needed to understand the role of self-efficacy in this association. If self-

362 efficacy is indeed a mediator, it could also be a target to reduce high sexual risk behavior,

363 especially among individuals with depression, through interventions such as behavioral

364 activation, problem-solving, and exploration of past successes and perceived competencies [41].

365

366 There are some limitations to consider when interpreting these data. First, clinic-based sampling

367 alone, as done in our study, may result in higher prevalence estimates for mental health disorders

368 than if non-clinic based sampling was also done [44]. However, if the prevalence of depression is

369 higher among those who seek care than those who do not, it would mean that the population with

370 the greatest need for mental healthcare services is perhaps the easiest to reach because they are

371 already in care. Roadside wellness clinics will be an important entry point to initiate provision of 
372 these services to truck drivers. Another limitation related to sampling is that our study

373 participants were recruited from two clinics in one geographical area, so we do not know how

374 similar or different these truck drivers are compared with truck drivers who attend clinics in

375 other areas of Kenya or East Africa. Second, our measure of sexual risk behavior was number of

376 condomless sex partners, which is not inclusive of all aspects of sexual risk [45]. Although

377 condomless sex with only a main partner would be considered lower sexual risk behavior

378 compared with condomless sex with multiple partners, most men in our study had more than one

379 sexual partner, even though most were married, and we adjusted for marital status and number of

380 sex partners in the multivariable model. Third, some variables may have been subject to

381 reporting bias. Because homosexuality is illegal in Kenya, it is understandable why study

382 participants may have been reluctant to discuss same-sex partners. In fact, there was only one

383 participant who reported previously having anal sex with another man. Similarly, participants

384 may have also been reluctant to fully disclose drug and alcohol use because of potential

385 consequences to their livelihood. Third, we did not have data on occupational stressors, which

386 may have acted as confounders or common causes of depression and sexual risk behavior.

387 Finally, as our study was cross-sectional, we do not know the direction of causality for the

388 association between depression and sexual risk behavior. Although the data were interpreted as

389 cross-sectional, measures were taken from two interviews that were six months apart, as this was

390 a secondary analysis and the original trial was not specifically designed to answer the research

391 questions in this paper. Because of the limited amount of time truck drivers had for interviews,

392 the PHQ-9 depression scale was administered six months later than the questionnaires assessing

393 demographic characteristics, HIV risk behavior, and self-efficacy, so measurement of our

394 exposure (depression) occurred after measurement of our outcome (sexual risk). Although 
395 depression status may have changed over the 6 months between the baseline and follow-up

396 interviews, we would not anticipate the association with sexual risk behavior to also change. It is

397 possible that an HIV diagnosis caused depression during follow-up, but only two participants

398 tested positive [24] and neither of these participants had a PHQ-9 score $\geq 10$. Nevertheless, a

399 longitudinal study is needed to establish the temporal order of events.

400

401 Beyond the truck driver population, there are major barriers to accessing mental health services,

402 particularly social stigma and dearth of mental health clinicians [46] in Kenya. Although most

403 stigma research in Kenya and sub-Saharan Africa has focused on HIV/AIDS, social stigma

404 regarding mental health disorders appears to be pervasive [47], but a neglected topic. Individuals

405 might be afraid to seek mental healthcare due to concerns about being labeled and stigmatized by

406 the community, co-workers, or healthcare providers. Because there are a critically low number of

407 mental healthcare providers in Kenya, integrating aspects of mental healthcare in services

408 provided by primary care clinicians and lay health workers must be considered $[48,49]$. This

409 remains complicated considering the contradictory findings about the impact of providers'

410 intervention on reducing symptoms of mental health disorders. For example, a trial in Zimbabwe

411 found that lay health workers had a positive impact on reducing symptoms of common mental

412 health disorders through a brief cognitive-behavioral intervention [50], whereas a trial in Kenya

413 found that a mental health training program for primary care clinicians failed to improve

414 diagnosis of mental health disorders [51].

415

416

\section{Conclusions}

418 The results of this study suggest an association between depression and sexual risk behavior, and 419 that this association might be mediated by general self-efficacy. Future research is needed to 
420 clarify the directionality of these associations. Despite frequent HIV risk-reduction counseling at

421 the roadside clinics included in this study, the prevalence of sexual risk behavior in our

422 participant population was high, emphasizing the importance of bolstering risk-reduction

423 strategies. The prevalence of depression was also high, which emphasizes the importance of

424 developing strategies to improve mental health diagnosis and treatment in this setting. For long-

425 distance truck drivers specifically, future research in sub-Saharan Africa should identify

426 occupational risk factors for depression and other mental health conditions to ensure that

427 evidence-based interventions can be better tailored to this population.

428

429

430

431

432

433

434

435

436

437

438

439

440

441

442

443

444

445

446

447

448

\section{Acknowledgements}

We thank the fieldworkers, Alice Opiyo, Deborah Ochungo, Lucy Wanjiru, and Oliver Simiyu, who recruited the study participants and conducted the interviews, the staff at the two participating North Star Alliance clinics who helped with recruitment, and the staff at the North Star Alliance Nairobi office who helped with administrative requirements, such as ethics committee applications. We also are grateful to the study participants who made this study possible.

\section{References}

1. Melchior M, Caspi A, Milne BJ, Danese A, Poulton R, Moffitt TE: Work stress precipitates depression and anxiety in young, working women and men. Psychol Med 2007, 37(8):1119-1129. 
449 2. Munce SE, Weller I, Robertson Blackmore EK, Heinmaa M, Katz J, Stewart DE: The 450 role of work stress as a moderating variable in the chronic pain and depression 451 association. J Psychosom Res 2006, 61(5):653-660.

452 3. Wang J: Work stress as a risk factor for major depressive episode(s). Psychol Med 2005, $453 \quad 35(6): 865-871$.

454 4. Wulsin L, Alterman T, Timothy Bushnell P, Li J, Shen R: Prevalence rates for depression 455 by industry: a claims database analysis. Soc Psychiatry Psychiatr Epidemiol 2014, 456 49(11):1805-1821.

457 5. Shattell M, Apostolopoulos Y, Sonmez S, Griffin M: Occupational stressors and the 458 mental health of truckers. Issues Ment Health Nurs 2010, 31(9):561-568.

459 6. da Silva-Junior FP, de Pinho RS, de Mello MT, de Bruin VM, de Bruin PF: Risk factors 460 for depression in truck drivers. Soc Psychiatry Psychiatr Epidemiol 2009, 44(2):125-129. 461 7. Fan ZJ, Bonauto DK, Foley MP, Anderson NJ, Yragui NL, Silverstein BA: Occupation 462 and the prevalence of current depression and frequent mental distress, WA BRFSS 2006 463 and 2008. Am J Ind Med 2012, 55(10):893-903.

464 8. Shattell M, Apostolopoulos Y, Collins C, Sonmez S, Fehrenbacher C: Trucking 465 organization and mental health disorders of truck drivers. Issues Ment Health Nurs 2012, 466 33(7):436-444.

467 9. Rice SM, Aucote HM, Eleftheriadis D, Moller-Leimkuhler AM: Prevalence and Co$468 \quad$ Occurrence of Internalizing and Externalizing Depression Symptoms in a Community $469 \quad$ Sample of Australian Male Truck Drivers. Am J Mens Health 2016. 
470 10. Shen S, Li Y, Zhou M, Zhang C, Jiang Y, Kang Y: Depression status and associated 471 factors in Chinese occupational truck drivers. Cell Biochem Biophys 2013, 67(3):1497$472 \quad 1500$.

473 11. Vakili M, Eslami Farsani SH, Hosseini SMH, Dehghani Tafti MH. Prevalence of 474 depression and its related factors among truck drivers in Yazd Province -2008. Iran $475 \quad$ Occupational Health 2010, 6:69-74.

476 12. Costenbader EC, Lancaster K, Bufumbo L, Akol A, Guest G: On the road again: concurrency and condom use among Uganda truck drivers. Afr J AIDS Res 2015, 478 14(2):117-125.

479 13. Morris CN, Ferguson AG: Sexual and treatment-seeking behaviour for sexually 480 transmitted infection in long-distance transport workers of East Africa. Sex Transm Infect 2007, 83(3):242-245.

482 14. Yaya I, Landoh DE, Saka B, Vignikin K, Aboubakari AS, N'Dri K M, Gbetoglo KD, 483 Edorh AM, Ahlegnan K, Yenkey HC, Toudeka AS, Pitché P: Consistent Condom Use during Casual Sex among Long-Truck Drivers in Togo. PLoS One 2016, 11(4):e0153264.

486

15. Botao C, Horth RZ, Frank H, Cummings B, Inguane C, Sathane I, McFarland W, Fisher 487 Raymond H, Young PW: Prevalence of HIV and Associated Risk Factors Among Long Distance Truck Drivers in Inchope, Mozambique, 2012. AIDS Behav 2016, 20(4):811820.

490

16. Smit J, Myer L, Middelkoop K, Seedat S, Wood R, Bekker LG, Stein DJ: Mental health 491 and sexual risk behaviours in a South African township: a community-based crosssectional study. Public Health 2006, 120(6):534-542. 
493 17. Nduna M, Jewkes RK, Dunkle KL, Shai NP, Colman I: Associations between depressive 494 symptoms, sexual behaviour and relationship characteristics: a prospective cohort study 495 of young women and men in the Eastern Cape, South Africa. J Int AIDS Soc 2010, 13:44. 496 18. Hill LM, Maman S, Kilonzo MN, Kajula LJ: Anxiety and depression strongly associated 497 with sexual risk behaviors among networks of young men in Dar es Salaam, Tanzania. AIDS Care 2016:1-7.

499

19. Wang YY, Jiang NZ, Cheung EF, Sun HW, Chan RC: Role of depression severity and 500 impulsivity in the relationship between hopelessness and suicidal ideation in patients with 501 major depressive disorder. J Affect Disord 2015, 183:83-89.

502

20. Bandura A. 2010. Self-Efficacy. Corsini Encyclopedia of Psychology. 1-3.

503 21. Wagner GJ, Holloway I, Ghosh-Dastidar B, Kityo C, Mugyenyi P: Understanding the 504 influence of depression on self-efficacy, work status and condom use among HIV clients in Uganda. J Psychosom Res 2011, 70(5):440-448.

506

507

508

509

510

511

512

513

514

515

22. Alvy LM, McKirnan DJ, Mansergh G, Koblin B, Colfax GN, Flores SA, Hudson S: Depression is associated with sexual risk among men who have sex with men, but is mediated by cognitive escape and self-efficacy. AIDS Behav 2011, 15(6):1171-1179.

23. Tucker A, Liht J, de Swardt G, Jobson G, Rebe K, McIntyre J, Struthers H: An exploration into the role of depression and self-efficacy on township men who have sex with men's ability to engage in safer sexual practices. AIDS Care 2013, 25(10):12271235.

24. Kelvin EA, George G, Mwai E, Nyaga E, Mantell JE, Romo ML, Odhiambo JO, Starbuck L, Govender K: Offering self-administered oral HIV testing to truck drivers in Kenya to increase testing: a randomized controlled trial. AIDS Care 2018, 30(1):47-55. 
516 25. Kenya HIV prevention revolution roadmap count down to 2030

$517 \quad$ [https://drive.google.com/file/d/0B6hn4-tQ6XTIOGZLS25Lbm5LTEU/edit]

518 26. Kenya AIDS progress report 2014 progress towards zero

519 [http://www.unaids.org/sites/default/files/country/documents/KEN_narrative_report_201

$520 \quad$ 4.pdf]

521 27. North Star Alliance. Annual Overview 2015. annualoverview.northstar-alliance.org.

522 28. Kroenke K, Spitzer RL, Williams JB: The PHQ-9: validity of a brief depression severity 523 measure. J Gen Intern Med 2001, 16(9):606-613.

524 29. Gelaye B, Williams MA, Lemma S, Deyessa N, Bahretibeb Y, Shibre T, Wondimagegn 525 D, Lemenhe A, Fann JR, Vander Stoep A, Andrew Zhou XH: Validity of the Patient $526 \quad$ Health Questionnaire-9 for depression screening and diagnosis in East Africa. Psychiatry 527 Res 2013, 210(2):653-661.

528 30. Hanlon C, Medhin G, Selamu M, Breuer E, Worku B, Hailemariam M, Lund C, Prince 529 M, Fekadu A: Validity of brief screening questionnaires to detect depression in primary 530 care in Ethiopia. J Affect Disord 2015, 186:32-39.

531 31. Schwarzer, R., \& Jerusalem, M. (1995). Generalized Self-Efficacy scale. In J. Weinman, 532 S. Wright, \& M. Johnston, Measures in health psychology: A user's portfolio. Causal and 533 control beliefs (pp. 35- 37). Windsor, England: NFER-NELSON.

534 32. Keyes CL, Wissing M, Potgieter JP, Temane M, Kruger A, van Rooy S: Evaluation of the 535 mental health continuum-short form (MHC-SF) in setswana-speaking South Africans.

536 Clin Psychol Psychother 2008, 15(3):181-192.

537 33. Bodner TE: What Improves with Increased Missing Data Imputations? Struct Equ $538 \quad$ Modeling 2008, 15(4):651-675. 
539 34. Berglund P, Heeringa SG. 2014. Multiple Imputation of Missing Data Using SAS. SAS

$540 \quad$ Institute.

541 35. Valeri L, Vanderweele TJ: Mediation analysis allowing for exposure-mediator

542 interactions and causal interpretation: theoretical assumptions and implementation with 543 SAS and SPSS macros. Psychol Methods 2013, 18(2):137-150.

544 36. Pearl J: Interpretation and identification of causal mediation. Psychol Methods 2014, 545 19(4):459-481.

546 37. Secor AM, Wahome E, Micheni M, Rao D, Simoni JM, Sanders EJ, Graham SM:

547 Depression, substance abuse and stigma among men who have sex with men in coastal $548 \quad$ Kenya. AIDS 2015, 29 Suppl 3:S251-259.

549 38. World Health Survey. Report of Kenya, 2003. Available at: www.who.int/healthinfo/survey/whsken-kenya.pdf. Acessed October 19, 2016.

551 39. Anderson AM, Ross MW, Nyoni JE, McCurdy SA: High prevalence of stigma-related 552 abuse among a sample of men who have sex with men in Tanzania: implications for HIV prevention. AIDS Care 2015, 27(1):63-70.

554 40. Beck J. Cognitive Therapy: Basics and Beyond. New York: Guilford Press; 1995.

555 41. Kamen C, Flores S, Etter D, Lazar R, Patrick R, Lee S, Koopman C, Gore-Felton C:

$556 \quad$ General self-efficacy in relation to unprotected sexual encounters among persons living 557 with HIV. J Health Psychol 2013, 18(5):658-666.

558 42. Bandura A: Human agency in social cognitive theory. Am Psychol 1989, 44(9):1175559 1184. 
560 44. Tak YR, Brunwasser SM, Lichtwarck-Aschoff A, Engels RC: The prospective

561 associations between self-eficacy and depressive symptoms from early to middle

562 adolescence: A cross-lagged model. J Youth Adolesc 2017, 46(4):744-756.

563 44. Patten SB: Selection bias in studies of major depression using clinical subjects. J Clin $564 \quad$ Epidemiol 2000, 53(4):351-357.

565 45. Aral SO: Sexual risk behaviour and infection: epidemiological considerations. Sex $566 \quad$ Transm Infect 2004, 80 Suppl 2:ii8-12.

567 46. Providing Sustainable Mental and Neurological Health Care in Ghana and Kenya:

568 Workshop Summary. Washington DC: 2016 by the National Academy of Sciences; 2016.

569 47. Ndetei DM, Mutiso V, Maraj A, Anderson KK, Musyimi C, McKenzie K: Stigmatizing 570 attitudes toward mental illness among primary school children in Kenya. Soc Psychiatry $571 \quad$ Psychiatr Epidemiol 2016, 51(1):73-80.

572 48. Jenkins R, Kiima D, Okonji M, Njenga F, Kingora J, Lock S: Integration of mental health 573 into primary care and community health working in Kenya: context, rationale, coverage $574 \quad$ and sustainability. Ment Health Fam Med 2010, 7(1):37-47.

575 49. Marangu E, Sands N, Rolley J, Ndetei D, Mansouri F. Mental healthcare in Kenya: 576 Exploring optimal conditions for capacity building. Afr J Prm Health Care Fam Med 577 2014, 6(1):682.

578 50. Chibanda D, Weiss HA, Verhey R, Simms V, Munjoma R, Rusakaniko S, Chingono A, 579 Munetsi E, Bere T, Manda E, Abas M, Araya R: Effect of a Primary Care-Based 580 Psychological Intervention on Symptoms of Common Mental Disorders in Zimbabwe: A 581 Randomized Clinical Trial. JAMA 2016, 316(24):2618-2626. 
582 51. Jenkins R, Othieno C, Okeyo S, Kaseje D, Aruwa J, Oyugi H, Bassett P, Kauye F: Short 583 structured general mental health in service training programme in Kenya improves 584 patient health and social outcomes but not detection of mental health problems - a 585 pragmatic cluster randomised controlled trial. Int J Ment Health Syst 2013, 7(1):25. 586 


\section{Table 1 (on next page)}

Demographic variables, risk behaviors, and other characteristics overall and by depression category 
1 Table 1. Demographic variables, risk behaviors, and other characteristics overall and by 2 depression category

3

\begin{tabular}{|c|c|c|c|c|c|}
\hline & $\begin{array}{c}\text { All } \\
\text { participants } \\
\text { (with } \\
\text { depression } \\
\text { data) }\end{array}$ & $\begin{array}{l}\text { None/minima } \\
\text { I depression }\end{array}$ & $\begin{array}{c}\text { Mild } \\
\text { depression }\end{array}$ & $\begin{array}{l}\text { Moderate- } \\
\text { severe } \\
\text { depression }\end{array}$ & P-value \\
\hline $\mathrm{n}(\%)$ & $284(100 \%)$ & $157(55.3 \%)$ & $59(20.8 \%)$ & $68(23.9 \%)$ & NA \\
\hline Age (years) & $\mathrm{N}=284$ & & & & \\
\hline $\begin{array}{r}\text { Mean }(\mathrm{SD}) / \\
\text { Median }(\mathrm{IQR})\end{array}$ & $\begin{array}{l}36.9(7.9) / \\
36.0(10.0)\end{array}$ & $\begin{array}{l}36.9(8.0) / \\
37.0(10.0)\end{array}$ & $\begin{array}{l}37.0(7.0) / \\
37.0(9.0)\end{array}$ & $\begin{array}{l}36.8(8.5) / \\
35.0(11.5)\end{array}$ & $.859^{\mathrm{a}}$ \\
\hline Married & $\mathrm{N}=282$ & & & & \\
\hline Yes, $\mathrm{n}(\%)$ & $234(83.0 \%)$ & $130(55.6 \%)$ & $50(21.4 \%)$ & $54(23.1 \%)$ & $.660^{\mathrm{b}}$ \\
\hline No, n $(\%)$ & $48(17.0 \%)$ & $25(52.1 \%)$ & $9(18.8 \%)$ & $14(29.2 \%)$ & \\
\hline $\begin{array}{l}\text { Secondary school } \\
\text { education or } \\
\text { higher }\end{array}$ & $\mathrm{N}=284$ & & & & \\
\hline Yes, $\mathrm{n}(\%)$ & $105(37.0 \%)$ & $57(54.3 \%)$ & $25(23.8 \%)$ & $23(21.9 \%)$ & $.589^{\mathrm{b}}$ \\
\hline No, n $(\%)$ & $179(63.0 \%)$ & $100(55.9 \%)$ & $34(19.0 \%)$ & $45(25.1 \%)$ & \\
\hline Religion & $\mathrm{N}=279$ & & & & \\
\hline Christian, n (\%) & $217(77.8 \%)$ & $117(53.9 \%)$ & $47(21.7 \%)$ & $53(24.4 \%)$ & $.436^{\mathrm{b}}$ \\
\hline $\begin{array}{r}\text { Non-Christian, } \mathrm{n} \\
(\%)\end{array}$ & $62(22.2 \%)$ & $39(62.9 \%)$ & $10(16.1 \%)$ & $13(21.0 \%)$ & \\
\hline Monthly income & $\mathrm{N}=268$ & & & & \\
\hline$<240$ USD, n (\%) & $71(26.5 \%)$ & $34(47.9 \%)$ & $10(14.1 \%)$ & $27(38.0 \%)$ & $.010^{\mathrm{b}}$ \\
\hline$\geq 240$ USD, n (\%) & $197(73.5 \%)$ & $112(56.9 \%)$ & $45(22.8 \%)$ & $40(20.3 \%)$ & \\
\hline $\begin{array}{l}\text { Years worked as } \\
\text { a truck driver }\end{array}$ & $\mathrm{N}=284$ & & & & \\
\hline $\begin{array}{r}\text { Mean }(\mathrm{SD}) / \\
\text { Median (IQR) }\end{array}$ & $\begin{array}{l}8.8(7.1) / \\
7.0(7.0)\end{array}$ & $\begin{array}{l}9.2(6.5) / 8.0 \\
(8.0)\end{array}$ & $\begin{array}{l}9.3(8.0) / 6.7 \\
(6.8)\end{array}$ & $\begin{array}{l}7.6(7.4) / 4.2 \\
(6.3)\end{array}$ & $.016^{\mathrm{a}}$ \\
\hline $\begin{array}{l}\text { Usually drives } \\
\text { alone }\end{array}$ & $\mathrm{N}=284$ & & & & \\
\hline Yes, $\mathrm{n}(\%)$ & $165(58.1 \%)$ & $97(58.8 \%)$ & $32(19.4 \%)$ & $36(21.8 \%)$ & $.372^{\mathrm{b}}$ \\
\hline No, n $(\%)$ & $119(41.9 \%)$ & $60(50.4 \%)$ & $27(22.7 \%)$ & $32(26.9 \%)$ & \\
\hline $\begin{array}{l}\text { Days away on } \\
\text { road in past } 30 \\
\text { days }\end{array}$ & $\mathrm{N}=277$ & & & & \\
\hline $\begin{array}{r}\text { Mean }(\mathrm{SD}) / \\
\text { Median }(\mathrm{IQR})\end{array}$ & $\begin{array}{l}21.6(5.5) / \\
23.0(5.0)\end{array}$ & $\begin{array}{l}21.5(5.6) / \\
22.0(5.0)\end{array}$ & $\begin{array}{l}21.7(5.4) / \\
22.0(5.0)\end{array}$ & $\begin{array}{l}21.9(5.5) / \\
24.0(5.0)\end{array}$ & $.766^{\mathrm{a}}$ \\
\hline $\begin{array}{l}\text { General self- } \\
\text { efficacy (score) }\end{array}$ & $\mathrm{N}=284$ & & & & \\
\hline $\begin{array}{r}\text { Mean }(\mathrm{SD}) / \\
\text { Median }(\mathrm{IQR})\end{array}$ & $\begin{array}{l}36.5(4.6) / \\
39.0(5.0)\end{array}$ & $\begin{array}{l}38.2(2.9) / \\
40.0(3.0)\end{array}$ & $\begin{array}{l}35.3(5.3) / \\
37.0(8.0)\end{array}$ & $\begin{array}{l}33.7(5.6) / \\
36.0(10.5)\end{array}$ & $<.001^{\mathrm{a}}$ \\
\hline
\end{tabular}




\begin{tabular}{|c|c|c|c|c|c|}
\hline $\begin{array}{l}\text { Alcohol use in } \\
\text { past year }\end{array}$ & $\mathrm{N}=284$ & & & & \\
\hline Yes, n $(\%)$ & $152(53.5 \%)$ & $79(52.0 \%)$ & $38(25.0 \%)$ & $35(23.0 \%)$ & $.168^{\mathrm{b}}$ \\
\hline No, n (\%) & $132(46.5 \%)$ & $78(59.1 \%)$ & $21(15.9 \%)$ & $33(25.0 \%)$ & \\
\hline $\begin{array}{l}\text { Drug use in past } \\
\text { yeard }^{\text {d }}\end{array}$ & $\mathrm{N}=283$ & & & & \\
\hline Yes, n (\%) & $9(3.2 \%)$ & $0(0.0 \%)$ & $1(11.1 \%)$ & $8(88.9 \%)$ & $<.001^{\mathrm{c}}$ \\
\hline No, n (\%) & $274(96.8 \%)$ & $129(47.1 \%)$ & $86(31.4 \%)$ & $59(21.5 \%)$ & \\
\hline $\begin{array}{l}\text { Number of sex } \\
\text { partners in past } 6 \\
\text { months }\end{array}$ & $\mathrm{N}=268$ & & & & \\
\hline $\begin{array}{r}\text { Mean } \\
(\mathrm{SD}) / \text { Median } \\
(\mathrm{IQR})\end{array}$ & $\begin{array}{l}2.8(4.1) / \\
2.0(3.0)\end{array}$ & $\begin{array}{l}2.6(5.4) / 2.0 \\
(2.0)\end{array}$ & $\begin{array}{l}2.4(1.7) / 2.0 \\
(2.0)\end{array}$ & $\begin{array}{l}3.5(3.5) / 2.0 \\
(4.0)\end{array}$ & $.085^{\mathrm{a}}$ \\
\hline $\begin{array}{l}\text { Number of } \\
\text { condomless sex } \\
\text { partners in past } 6 \\
\text { months }\end{array}$ & $\mathrm{N}=275$ & & & & \\
\hline $\begin{array}{r}\text { Mean } \\
(\mathrm{SD}) / \text { Median } \\
(\mathrm{IQR})\end{array}$ & $\begin{array}{l}1.5(1.6) / \\
1.0(1.0)\end{array}$ & $\begin{array}{l}1.2(1.1) / 1.0 \\
(0.0)\end{array}$ & $\begin{array}{l}1.3(1.1) / 1.0 \\
(0.0)\end{array}$ & $\begin{array}{l}2.2(2.6) / 1.0 \\
(2.0)\end{array}$ & $.003^{\mathrm{a}}$ \\
\hline None, $\mathrm{n}(\%)$ & $40(14.6 \%)$ & $23(57.5 \%)$ & $11(27.5 \%)$ & $6(15.0 \%)$ & $.038^{\mathrm{b}}$ \\
\hline One, n $(\%)$ & $160(58.2 \%)$ & $73(45.6 \%)$ & $54(33.8 \%)$ & $33(20.6 \%)$ & \\
\hline $\begin{array}{r}\text { Two or more, } \mathrm{n} \\
(\%)\end{array}$ & $75(27.3 \%)$ & $27(36.0 \%)$ & $21(28.0 \%)$ & $27(36.0 \%)$ & \\
\hline
\end{tabular}

4 IQR, interquartile range; SD, standard deviation; USD, US dollars.

5 Some percentages may not add up to $100 \%$ due to rounding.

6 aKruskall-Wallis test.

7 bPearson's chi-square test.

8 'Fisher's exact test.

9 dAll participants who reported drug use also reported alcohol use. Drug use was not included in

10 the regression models because of small numbers of participants in categories. 


\section{Table 2 (on next page)}

Poisson regression models examining the association of depression and other variables with number of condomless sex partners 
1 Table 2. Poisson regression models examining the association of depression and other

2 variables with number of condomless sex partners

\begin{tabular}{|c|c|c|c|}
\hline & Crude models $^{\mathrm{a}}$ & Multivariable model $^{b}$ & $\begin{array}{l}\text { Multivariable model } \\
\text { with imputed data }\end{array}$ \\
\hline & cPR $(95 \%$ CI); p-value & $\begin{array}{c}\text { aPR }(95 \% \mathrm{CI}) \\
\text { p-value }\end{array}$ & $\begin{array}{c}\text { aPR }(95 \% \mathrm{CI}) ; \\
\text { p-value }\end{array}$ \\
\hline & & $\mathrm{N}=236$ & $\mathrm{~N}=305$ \\
\hline Depression & $\mathrm{N}=275$ & & \\
\hline None/minimal & Reference & Reference & Reference \\
\hline Mild & $\begin{array}{c}1.08(0.84-1.37) \\
p=.563\end{array}$ & $\begin{array}{c}1.16(0.88-1.52) \\
\mathrm{p}=.290\end{array}$ & $\begin{array}{c}1.22(0.95-1.56) ; \\
\mathrm{p}=.124\end{array}$ \\
\hline Moderate-severe & $\begin{array}{c}1.80(1.43-2.26) ; \\
\mathrm{p}<.001\end{array}$ & $\begin{array}{c}1.63(1.25-2.12) \\
\mathrm{p}<.001\end{array}$ & $\begin{array}{c}1.62(1.26-2.08) ; \\
p<.001\end{array}$ \\
\hline Age (years) & $\mathrm{N}=296$ & & \\
\hline & $\begin{array}{c}1.00(0.99-1.01) \\
\mathrm{p}=.817\end{array}$ & $\begin{array}{c}1.01(0.99-1.03) ; \\
p=.720\end{array}$ & $\begin{array}{c}1.01(0.99-1.02) \\
\mathrm{p}=.360\end{array}$ \\
\hline Married & $\mathrm{N}=293$ & & \\
\hline Yes & $\begin{array}{c}1.58(1.17-2.12) \\
p=.003\end{array}$ & $\begin{array}{c}2.12(1.41-3.19) \\
p<.001\end{array}$ & $\begin{array}{c}1.67(1.20-2.32) \\
p=.003\end{array}$ \\
\hline No & Reference & Reference & Reference \\
\hline $\begin{array}{l}\text { Secondary school } \\
\text { education or higher }\end{array}$ & $\mathrm{N}=296$ & & \\
\hline Yes & $\begin{array}{c}0.69(0.57-0.85) \\
\mathrm{p}<.001\end{array}$ & $\begin{array}{c}0.79(0.61-1.02) ; \\
\mathrm{p}=.065\end{array}$ & $\begin{array}{c}0.73(0.58-0.92) \\
\mathrm{p}=.007\end{array}$ \\
\hline No & Reference & Reference & Reference \\
\hline Religion & $\mathrm{N}=290$ & & \\
\hline Christian & Reference & Reference & Reference \\
\hline Non-Christian & $\begin{array}{c}1.26(1.02-1.56) ; \\
\mathrm{p}=.032\end{array}$ & $\begin{array}{c}1.37(1.02-1.82) ; \\
\mathrm{p}=.034\end{array}$ & $\begin{array}{c}1.34(1.03-1.73) \\
p=.029\end{array}$ \\
\hline $\begin{array}{l}\text { Monthly trucking } \\
\text { income }\end{array}$ & $\mathrm{N}=279$ & & \\
\hline$<<240$ USD & Reference & Reference & Reference \\
\hline$\geq 240$ USD & $\begin{array}{c}0.64(0.52-0.77) \\
\mathrm{p}<.001\end{array}$ & $\begin{array}{c}0.76(0.59-0.97) \\
p=.029\end{array}$ & $\begin{array}{c}0.72(0.58-0.90) \\
p=.003\end{array}$ \\
\hline $\begin{array}{l}\text { Years worked as a } \\
\text { truck driver }\end{array}$ & $\mathrm{N}=294$ & & \\
\hline & $\begin{array}{c}0.98(0.97-1.00) \\
\mathrm{p}=.010\end{array}$ & $\begin{array}{c}0.98(0.96-1.00) \\
p=.055\end{array}$ & $\begin{array}{c}0.98(0.96-1.00) \\
p=.017\end{array}$ \\
\hline Usually drives alone & $\mathrm{N}=296$ & & \\
\hline Yes & $\begin{array}{c}1.43(1.19-1.72) \\
\mathrm{p}<.001\end{array}$ & $\begin{array}{c}1.16(0.92-1.47) ; \\
p=.220\end{array}$ & $\begin{array}{c}1.10(0.89-1.34) ; \\
p=.383\end{array}$ \\
\hline No & Reference & Reference & Reference \\
\hline \multirow[t]{2}{*}{$\begin{array}{l}\text { Nights away on road in } \\
\text { past } 30 \text { days }\end{array}$} & $\mathrm{N}=288$ & & \\
\hline & $0.99(0.97-1.01)$ & 0.98 (0.96-1.00; & 0.99 (0.98-1.01); \\
\hline
\end{tabular}




\begin{tabular}{|l|c|c|c|}
\hline \multicolumn{1}{|l|}{$\begin{array}{l}\text { Alcohol use in past } \\
\text { year }\end{array}$} & $\mathrm{p}=.183$ & $\mathrm{p}=.106$ & $\mathrm{p}=.475$ \\
\hline \multicolumn{1}{|c|}{ Yes } & $\begin{array}{c}1.14(0.95-1.38) ; \\
\mathrm{p}=.158\end{array}$ & $\begin{array}{c}1.11(0.87-1.42) ; \\
\mathrm{p}=.400\end{array}$ & $\begin{array}{c}1.06(0.86-1.31) ; \\
\mathrm{p}=.593\end{array}$ \\
\hline \multicolumn{1}{|c|}{ No } & $\mathrm{Reference}$ & Reference & Reference \\
\hline $\begin{array}{l}\text { Number of sex } \\
\text { partners in the past 6 } \\
\text { months }\end{array}$ & $\mathrm{N}=288$ & & \\
\hline & & & $1.04(1.03-1.06) ;$ \\
& $1.04(1.03-1.05) ;$ & $1.04(1.03-1.05) ;$ & $\mathrm{p}<.001$ \\
\hline
\end{tabular}

3 aNot adjusted for any other variables.

$4 \quad{ }^{b}$ Adjusted for clinic location in addition to the other variables listed.

5 aPR, adjusted prevalence ratio; $\mathrm{cPR}$, crude prevalence ratio; USD, US dollars.

6

7 